интересов различных групп населения и проводить эффективную политику, направленную на обеспечение благосостояния всех членов общества.

1. Усова Ю.В. Особенности формирования элиты в современном политическом пространстве // Теория и практика общественного развития. 2013. №4. С. 209-213.

2. Булатов А.Г. Региональные элиты как кадровый резерв для федеральных органов государственной власти: механизмы и принципы рекрутирования // Гуманитарные науки. Вестник Финансового университета. 2018. №5 (35). С. 93 - 96.

3. Гончаренко Я.В. Политическая элита России: современные механизмы рекрутинга // Русская политология. 2017. №2 (3). С. 5-9.

4. Шарин И.А. Рекрутирование региональных политических элит // Скиф. 2020. №4 (44). С.510 - 515.

5. Гаман-Голутвина О.В. Политические элиты как объект исследований в отечественной политической науке // Полит. наука. 2016. №2. С. 38-73.

6. Гусов М.Ю. Перспективные пути и способы преодоления маргинального состояния современных российских политико-элитных групп // Власть. 2017. №5. С. $168-173$.

\title{
Хлопов О.А. \\ Ядерная политика Китая в контексте российско-китайского стратегического партнерства
}

ФБГОУ ВО "Российский государственный гуманитарный университет" (Россия, Москва)

doi: 10.18411/trnio-09-2021-101

\section{Аннотация}

В статье анализируется ядерная политика Китая в контексте российско-китайского стратегического партнерства и изменяющегося баланса сил в мировой политики. Сегодня Китай занимается широкой модернизацией своих стратегических и других ядерных сил, включая усовершенствованные баллистические ракеты наземного базирования и подводных лодок, а также летательные аппараты с ядерным оружием. Роль ядерного оружия в международной политике остается жизненно важной, поскольку оно стало элементом стратегической стабильности, инструментом достижения национальных интересов государства, а ядерная модернизация Китая направлена на повышения статуса глобальной державы и защиты своего суверенитета. Автором отмечается, что КНР использует ядерное оружие как средства сдерживания неазиатских держав от вмешательства в определяемые самим собой ключевые зоны своей безопасности.

Ключевые слова: ядерное оружие, сдерживание, стратегическая стабильность, баланс сил, международные отношения, КНР, Россия, США.

\section{Abstract}

The article analyzes China's nuclear policy in the context of the Russian-Chinese strategic partnership and the changing balance of power in world politics. Today, China is engaged in extensive modernization of its strategic and other nuclear forces, including advanced land-based ballistic missiles and submarines, as well as nuclear-armed aircraft. The role of nuclear weapon in international politics remains vital, since it hase become an element of strategic stability, an instrument for achieving the national interests of a state, and China's nuclear modernization is aimed at raising the status of a global power and protecting its sovereignty. The author argues that the PRC uses nuclear weapons as a means of deterring non-Asian powers from interfering in the key zones of its security determined by itself.

Keywords: nuclear weapons, deterrence, strategic stability, balance of power, international relations, PRC, Russia, USA. 
Ядерное оружие продолжает играть очень важную роль в современных международных отношениях.. Отношения между Россией и США в этой сфере определяются стратегическим балансом сил, характеризующимся высокой степенью взаимной уязвимости; озабоченность, по поводу того, что другая сторона сможет перехватить или даже упредить значительную часть своих сил возмездия, особенно с использованием новых технологий. Учитывая возможность конфликта между НАТО и Россией, эти факторы означают, что ядерному оружию, а также оборонной стратегии и позициям в более широком смысле, уделяется все большее внимание, и это внимание, вероятно, будет только расти. Меры по контролю над вооружениями и стабильности станут более ценными и целесообразными, чтобы попытаться снизить вероятность возникновения конфликта или его эскалации, если это произойдет.

Стратегический баланс ядерных сил между США и Россией сегодня и, по крайней мере, в краткосрочной и среднесрочной перспективе, по-прежнему определяется, как и в течение многих лет, очень высокой степенью взаимной уязвимости. Проще говоря, обе стороны имеют возможность нанести беспрецедентные разрушения друг другу посредством применения ядерного оружия даже перед лицом решительных усилий другой стороны по упреждению или защите от него.

Влияние российско-китайское партнерства на глобальный порядок XXI в. Мировая политика после окончания "холодной войны переживает кризис. При президенте Д. Трампе США отказались от глобального лидерства, вместо этого прибегнув к неприкрытому преследованию национальных интересов под лозунгами «Америка прежде всего» и «Сделаем Америку снова великой». Европа начинает распадаться по культурным и нормативным признакам, поскольку либеральный консенсус рушится перед лицом конфликтов по поводу идентичности, роста популистского национализма и распространения авторитарных ценностей. Трансатлантические отношения пострадали больше, чем когдалибо после Суэцкого кризиса 1956 г., и само понятие унитарного «Запада» стало подозрительным.

Авторитет ведущих западных держав в международных институтах редко казался слабее. Но, несмотря на кризис либерализма и либерального порядка, пост-западная международная система еще не появилась на ее месте. Китай, Россия и Индия заявляют о себе как о глобальных игроках.

Однако многополярная или «полицентрическая» система пока не сформировалась. Соединенные Штаты могут испытывать трудности и внутренние проблемы, но они, вероятно, по-прежнему останутся ведущей державой в мире в следующие два десятилетия, а возможно, и намного дольше [1]. Европа останется неотьемлемой частью мировых дел, даже если она будет претерпевать изменения и трансформации.

Пост-западные нормы и институты изо всех сил пытаются сохраниться. Даже относительно успешный Азиатский банк инфраструктурных инвестиций (АБИИ) является лишь одной из нескольких организаций, финансирующих проекты развития в Евразии, наряду с Азиатским банком развития (АБР) и Всемирным банком. Возможно, наиболее успешным новым многосторонним механизмом может оказаться Всеобъемлющее региональное экономическое партнерство (ВРЭП), объединяющее Китай, десять государствчленов АCЕАН, а также Японию, Южную Корею, Австралию и Новую Зеландию.

На первый взгляд, Пекин и Москва почти идентичных взглядов на международные дела. Они соглашаются по вопросам общих принципов, таких как необходимость многополярного или «полицентричного» порядка, в котором больше не будет доминировать Америка, государственный суверенитет имеет важное значение. Их позиции также совпадают по множеству более конкретных вопросов, включая «киберсуверенитет», Иран, Северную Корею, противодействие противоракетной обороне и поддержку Большой Евразии. Даже в областях, которые когда-то казались проблемными, таких как Центральная Евразия и Арктика, их взаимодействие протекало на удивление гладко. 
Политические соображения и соображения безопасности, лежащие в основе китайскороссийских отношений, подкрепляются более крупными стратегическими расчетами. Хотя Пекин и Москва несколько различаются в своих взглядах на международный порядок и глобализацию под руководством Запада, каждая из них рассматривает США как явную и реальную опасность для своих геополитических интересов.

Для России партнерство с Китаем также представляет собой фактор, увеличивающий силу и влияние России во всем мире. Россия имеет гораздо больший международный вес в связи с Китаем, чем сама по себе.

Стратегические мотивы Китая несколько иные. Хорошие отношения с Россией нужны ему не как средство увеличения силы, а как страхование. Китайско-российское сотрудничество играет центральную роль в реализации основных внешнеполитических целей Китая, таких как Инициатива «Один пояс, один путь». В связи с соглашением 2015 г. между Экономическим поясом Шелкового пути (ЭПШП) и Евразийским экономическим союзом (ЕАЭС) оказалось незаменимой мерой укрепления доверия, помогающей нейтрализовать опасения России по поводу стратегического вытеснения Китаем.

В КНР признают влияние России в мире, которая остается ядерной сверхдержавой и крупнейшим и сильнейшим соседом Китая. Китайские политики усвоили уроки западного опыта отношений с Москвой. Какой бы отсталой или слабой ни выглядела Россия, она сохраняет способность расстраивать или сводить на нет цели даже самых могущественных стран, включая Соединенные Штаты и Китай.

Дипломатическое сотрудничество России и Китая и совпадающие представления о проблеме ядерной безопасности. Независимо от различных процессов, позиций и приоритетов интеграции Китая и России в существующую международную систему, две крупные евразийские державы значительно адаптировались к ее институтам и различным региональным многосторонним форумам. К ним относятся МВФ, Всемирный банк, АТЭС, BTO, G-20, саммиты по ядерной безопасности, 26 и два «шестисторонних переговоров» по ядерному обеспечению КНДР (с 2003 г.) и Ирана (с 2006 г.) [2]. Без адаптации Китая и России к глобальным институтам и участия в них, какими бы неудобными они ни были, мир был бы совсем другим. Но взаимодействие дало неоднозначные результаты с точки зрения их интересов.

В сфере дипломатического сотрудничества Китай и Россия демонстрируют совместное сопротивление попыткам Запада использовать силу для устранения и смены неугодных правительств или оказания политического и экономического давления на государства, которые США и их западные союзники считают виновными в нарушениях прав человека.

В 2007 г. совместное вето Китая и России заблокировало резолюцию ООН по Мьянме. В 2008 г. аналогичное вето было наложено, чтобы защитить Зимбабве Мугабе от порицания. Наиболее показательный пример - Китай и Россия совместно наложили вето на четыре поддержанные США резолюции по Сирии - 4 октября 2011 г ;; 4 февраля 2012 г ;; 19 июля 2012 г.; и 22 мая 2014 г. [3], которая помешала усилиям США, вместе с Францией, Великобританией, Германией и Португалией, по свержению правительства Б.Асада. США и их союзники подвергли критике вето и обвинили Москву и Пекин в том, что они выиграли время для президента Б. Асада, чтобы разгромить оппозицию [4]. Сьюзан Райс, посол США в $\mathrm{OOH}$, заявила, что США «возмущены» и «возмущены». [5] По словам представителей ООН, попытки США и их союзников ввести санкции против Сирии встретили «ожесточенное сопротивление» со стороны России и Китая. На встрече в 2014 году в Пекине российские и китайские лидеры, поздравляли друг друга с предотвращением интервенции Запада, которая, с их точки зрения, значительно усугубила бы положение и подорвала бы любые шаги к мирному урегулированию конфликта.

В начале 1990-х гг. не было совместного вето Китая и России; однако после 2007 г. половина вето России и все вето Китая в СБ ООН были совместными вето Китая и России. 
Россия и Китай также активизировали сотрудничество в многосторонних форматах, таких как ШОС и БРИКС. 15 июля 2014 г. две страны определили повестку дня для Банка развития БРИКС (Новый банк развития) с пулом резервной валюты, который получил название "Соглашения об условных резервах" и составил \$100 млрд. Банк со штаб-квартирой в Шанхае представляет собой попытку сломить доминирующее положение доллара США в мировой торговле, а также таких поддерживаемых долларом институтов, как Международный валютный фонд (МВФ) и Всемирный банк, оба из которых возглавляются США, институты, в которых страны БРИКС не имеют большого влияния.

Такое институциональное сотрудничество между двумя странами сопровождается сближающимися оценками внешних угроз. Анализ протоколов встреч в рамках консультаций по вопросам безопасности между КНР и РФ показывает растущую озабоченность по поводу «американского фактора» в мировой политике и согласие о необходимости совместной реакции Китая и России.

Критика и осуждение политики США в Азии и других странах как «все более угрожающей», а также демонстрация намерений противостоять растущей американской угрозе стали неотъемлемыми нормами в отношениях между Китаем и Россией в области безопасности. Именно здесь отношения Китая и России резко контрастируют с отношениями Китая и США: во взаимодействии с США или любой другой страной.

Подходы России и КНР $к$ проблеме ядерной безопасности. Как страна, ориентированная на безопасность, Россия, похоже, больше заинтересована и, возможно, способна взаимодействовать с многосторонними форумами для управления глобальной безопасностью. Это неудивительно, потому что Россия - одна из двух ядерных сверхдержав мира.

Помимо участия в двух шестисторонних переговорах, Москва также более активна, чем Пекин, по более широким вопросам военной и гражданской ядерной безопасности.

В 2006 г. В.Путин и Дж. Буш-мл. инициировали Глобальную инициативу по борьбе с ядерным терроризмом (ГИБАЯТ), в которую сейчас входят 82 государства-члена, цель которой заключается в укреплении глобального потенциала по предотвращению, обнаружению и реагированию на ядерный терроризм путем проведения многосторонних мероприятий, направленных на укрепление планов, политик, процедур и взаимодействия стран-партнеров.

Более активная позиция России в отношении управления ядерной безопасностью - это не просто вопрос опыта, накопленного в ходе переговоров с Западом о контроле над вооружениями времен холодной войны. Основанные на правилах механизмы международной безопасности снимут озабоченность по поводу безопасности. По тем же причинам Москва, взяв на себя обязательства по нескольким глобальным механизмам безопасности, таким как Инициатива по предотвращению распространения, возглавляемая США группа, которая пытается предотвратить торговлю оружием массового уничтожения [6]. Режим контроля за ракетной технологией и Договор по открытому небу, который позволяет странам НАТО и бывшим советским республикам проводить воздушную разведку над территорией друг друга. Россия также ратифицировала Договор о всеобъемлющем запрещении ядерных испытаний (ДВЗЯИ), чего еще предстоит сделать Китаю.

Иногда попытки Москвы интегрировать Россию в глобальные и региональные институты превосходили ожидания Запада. Россия в начале 2000-х гг. была готова сотрудничать и отвечать взаимностью, возможно, больше, чем ожидал Запад. Президент России стал первым главой иностранного государства, который позвонил президенту США после терактов 11 сентября 2001 г., после чего Россия активно обменивалась разведданными и оказывала материально-техническую поддержку силам НАТО в Афганистане. К разочарованию Кремля, Буш ответил на попытки Путина выйти через три месяца из Договора по ПРО, краеугольного камня стратегической стабильности между США и Россией. 
На более фундаментальном уровне в интересах России поддерживать рабочие отношения с Западом, особенно с Соединенными Штатами. Вот почему Путин решил не принимать немедленных ответных мер на санкции, введенные администрацией Б.Обамы в конце 2016 г., хотя в конечном итоге он сделал это после одобрения Конгрессом США дополнительных санкций в июле 2017 г. [7].

Беспрецедентная сдержанность Кремля была дополнительно подчеркнута его продолжающимся сотрудничеством с Вашингтоном по Сирии, Ирану, Северной Корее и борьбе с терроризмом, во всех областях, которые имеют прямое значение для глобального управления с Западом [8].

По сравнению с активным участием России в глобальных институтах безопасности участие КНР стало избирательным. Китай активно участвовал в двух шестисторонних переговорах. Он также подписал Конвенцию о биологическом оружии и Конвенцию о химическом оружии. Вместе с Россией Китай участвовал в вывозе и ликвидации химического оружия в Сирии.

Возможно, самая большая разница между Китаем и Россией заключается в том, что Пекин не участвовал в переговорах по контролю над вооружениями с Вашингтоном по нескольким причинам. Один из них заключается в том, что Китай никогда не сообщал подробностей о своем ядерном арсенале. Различные западные оценки указывают на диапазон из 80-300 боеголовок, готовых к развертыванию и хранению. В «Белой книге по обороне Китая» 2008 года используется термин «бережливые и эффективные» для описания небольших стратегических сил Китая [9].

Следует отметить, что решение о сохранении небольших ядерных сил было принято в конце 1950-х - начале 1960-х гг., когда Китай страдал от экономических ограничений. В XXI веке, когда экономика Китая намного больше и крепче, размер его стратегических сил остается ограниченным Низкий запас ядерного оружия в Китае сопровождается его декларируемой стратегией неприменения первым. Он утверждает, что все государства, обладающие ядерным оружием, должны принять это правило, как это сделал Китай, чтобы снизить свои ядерные пороги, что в конечном итоге приведет к международно-правовому соглашению. В этом контексте Китай рассматривает свою политику "не применения первым ядерного оружия" как наиболее тесную связь с контролем над ядерными вооружениями.

Однако ядерная позиция Китая с низким уровнем запасов и высоким порогом оказалась под вопросом после президентских выборов в США в 2016 г. Горячие дебаты разгорелись в ответ на «стратегическое высокомерие» Д. Трампа по отношению к Китаю и его теплую и холодную риторику в отношении Китая по вопросам торговли, Тайваня и ядерных вооружений.

В этом контексте китайская мобильная межконтинентальная баллистическая ракета DF-31AG, которая дебютировала на военном параде, посвященном девяностолетию НОАК 30 июля 2017 г., была описана как крайне необходимое средство для сокращения «ракетного разрыва» между минималистичным ядерным арсеналом Китая и огромные запасы в США и России.

Но даже при гораздо большем ядерном арсенале маловероятно, что Пекин изменит свою нынешнюю ядерную стратегию "не применения первым ядерного оружия". В этом отношении долгосрочная безопасность Китая может быть усилена на глобальном уровне за счет режима контроля над ядерными вооружениями, включающего три основных компонента: многосторонность, дифференцированная ответственность и сокращение, а также поддержание стратегической стабильности.

По мнению Пекина, роль ООН в этой области должна быть максимальной, а законные и разумные интересы безопасности всех стран должны уважаться и учитываться. Соответственно, Китай остается активным в процессе рассмотрения действия Договора о нераспространении ядерного оружия (ДНЯО), особенно в восьмой Конференции по рассмотрению действия ДНЯО в 2010 г. Он выступает за скорейшее вступление в силу ДВЗЯИ и скорейшие переговоры по расщепляющемуся оружию. Договор о запрещении 
производства материалов на Конференции по разоружению в Женеве. На региональном уровне Китай поддерживает создание зон, свободных от ядерного оружия, в регионе АСЕАН и Центральной Азии, а также усилия по созданию зоны, свободной от ядерного оружия, на Ближнем Востоке. В соответствии с требованиями Подготовительной комиссии ДВЗЯИ она создала 12 международных станций и лабораторий мониторинга, включая шесть станций первичного сейсмологического мониторинга, три радионуклидные станции, Пекинскую радионуклидную лабораторию, Китайский национальный центр данных и одну инфразвуковую станцию.

В более общем плане Китай настаивает на том, чтобы страны, обладающие крупнейшими ядерными арсеналами, несли главную ответственность за ядерное разоружение. Это должно быть сделано поддающимся проверке, необратимым и юридически обязательным образом. Когда условия будут «подходящими», другие государства, обладающие ядерным оружием, включая Китай, могут присоединиться к многосторонним переговорам по ядерному разоружению.

Наконец, КНР и Россия вместе утверждает, что программа США по глобальной противоракетной обороне (ПРО) наносит ущерб международной стратегической стабильности, в частности, минималистской политике развертывания Китая.

Китайско-российское сотрудничество служит обеим сторонам. Это не обязательно должно быть взаимодействие равных или даже одинаковая выгода для обоих, и не всегда предполагает совпадение взглядов на внешний мир. Но важно то, что отношения являются и считаются взаимовыгодными. Одна из сильных сторон китайско-российского партнерства заключается в том, что оно лишено идеологического багажа, подорвавшего так называемую «нерушимую дружбу» в 1950-х гг. У обеих сторон есть четкое понимание того, чего они хотят, и уверенность в том, что они могут достичь своих целей. Это придает их партнерству реальную силу и устойчивость.

Модернизация ядерных сил КНР. Стратегия национальной безопасности США 2017 г. администрации Д. Трампа определила "ревизионистские силь Китая и России как потенциальных равных конкурентов" [10]. Вероятно, в будущих переговорах такого типа может участвовать КНР, но повестка дня для этого может быть сложной. Взгляды Китая на военную стратегию и роль ядерного сдерживания во многом отличаются от российской или американской точки зрения.

Растущая экономическая мощь Китая, безусловно, позволит ему улучшить свой военный потенциал, в том числе ядерное оружие. Один вопрос, на который нет ответа, заключается в том, насколько далеко Китай готов зайти в модернизации своих ядерных сил большой дальности и что это может означать для усилий по привлечению Китая в качестве партнера в области контроля над ядерными вооружениями.

Многостороннее соглашение о контроле над ядерными вооружениями обеспечивает ядерно-стратегическую стабильность среди большинства признанных в настоящее время государств, обладающих ядерным оружием.

КНР имеет планы по модернизации своих ракетно-ядерных и бомбардировочных сил связаны с его политическими и военными целями в ближайшей и долгосрочной перспективе. Согласно анализу корпорации RAND, Россия представляет собой более серьезную военную проблему для США, но Китай является более многообещающим конкурентом за глобальное влияние в последующие десятилетия [11]. Военная модернизация Китая учитывала его статус как ядерной державы и необходимость установить основу для текущего и будущего планирования ядерных сил [12].

Оценки разведки США о текущем ядерном военном потенциале Китая подвергаются сомнению из-за нежелания Китая предоставлять общедоступную информацию по этому поводу. Тем не менее, есть соответствующие обобщения относительно ядерных программ и политики Китая, "Китай разработал новую передвижную межконтинентальную баллистическую ракету, новую версию своей межконтинентальной баллистической ракеты шахтного базирования с несколькими боеголовками и новую баллистическую ракету, 
запускаемую с подводных лодок. Объявив о выпуске нового стратегического бомбардировщика, способного нести ядерный заряд, Китай вскоре представит свою собственную ядерную триаду, демонстрируя приверженность Китая расширению роли и центральной роли ядерных сил в военных устремлениях Пекина"[13].

Китай часто описывают как государство, которое стремится лишь к минимальному или конечному ядерному сдерживанию. Это предположение подразумевает, что Китай будет доволен сохранением небольшого количества оружия, которое может наносить ответные удары по городам противника. С другой стороны, текущая и планируемая ядерная модернизация Китая оставляет открытыми двери для более мощных средств ядерного сдерживания: в зависимости от возможностей будущих наступательных ядерных сил России и США и противоракетной обороны США, среди других переменных [14].

Китай моделирует свою ядерную программу, исходя из предположения, что она должна соответствовать России или США во всех аспектах военного ядерного потенциала. В то же время Китай стремится к тому, чтобы его всерьез воспринимали как крупную ядерную державу, и чтобы иметь эффективное средство сдерживания [15]. Ядерная программа Китая включает беспрецедентную модернизацию его межконтинентальных баллистических ракет, БРПЛ и бомбардировщиков, а также разработку ядерных боеголовок следующего поколения с меньшей мощностью и высокой точностью.

Как отмечается в передовой статье китайской газеты "Global Times", "поскольку американское стратегическое сдерживание Китая становится все более интенсивным, я хотел бы еще раз напомнить, что у нас много неотложных задач, но среди наиболее важных из них - быстрое увеличение количества введенных в эксплуатацию ядерных боеголовок и DF-41, стратегических в арсенале Китая есть ракеты, способные поражать дальность действия и обладающие высокой живучестью. Это краеугольный камень стратегического сдерживания Китая против США. Мы должны быть готовы к интенсивному противостоянию между Китаем и США. В этом сценарии большое количество баллистических ракет межконтинентального радиуса действия, запускаемых с подводных лодок (Dongfeng-41, JL-2 и JL-3) составят основу нашей стратегической воли. Количество ядерных боеголовок Китая должно достигнуть того количества, которое заставит американскую элиту содрогнуться, если у них возникнет идея вступить в военную конфронтацию с Китаем. Исходя из этого, мы можем спокойно и активно урегулировать разногласия с Вашингтоном, чтобы избежать незначительного инцидента, который может спровоцировать войну" [16].

Ядерный арсенал Китая по оценкам Стокгольмского международного института исследования проблем мира составляет 350 боеголовок, в то время как США и Россия имеют около 6000 боеголовок. Пентагон заявляет, что Китай как минимум удвоит свой арсенал в течении следующих 10 лет.

Наряду с этим китайский флот атомных подводных лодок поддерживает амбициозную стратегию противодействия, направленную на сдерживание военного вмешательства США в поддержку союзных интересов в Азии вопреки желанию Китая [17]. Кроме того, эксперты предупреждают о том, что китайские военные возможности для проецирования силы расширяются, так же как и его стратегические устремления [18].

При президенте Си Цзиньпине Китай также стал более настойчив по другим военностратегическим вопросам, включая: строительство китайских военных аэродромов на спорных островах в Южно-Китайском море; заявление о расширенных «опознавательных зонах противовоздушной обороны», для транзита которых потребуется разрешение Китая; и разработка большего количества кибероружия для поддержки своей дипломатической и военной стратегии.

Китайская дипломатия также создает дополнительное пространство для маневра по контролю над вооружениями и другим вопросам. Как отметил российский эксперт по контролю над ядерными вооружениями Алексей Арбатов, «осторожная и многовекторная» 
политика Пекина «позволила ему взять на себя роль, к которой традиционно стремилась Россия, - роль балансира между Востоком и Западом. Фактически, именно Россия с ее новой политикой «евразийства» превратилась в Восток» [19]. С другой стороны, политические и военные цели Китая в Азии и во всем мире отличаются от целей США и России, отражая цели Китая и осознание собственных интересов и предполагаемой роли в формирующемся мировом порядке [20]. Военная модернизация Китая призвана поддержать его растущий глобальный статус и расширенный набор международных интересов: сосредоточение внимания на «инвестициях и инфраструктуре для поддержки ряда миссий за пределами периферии Китая, включая «проецирование мощности, безопасность морских путей, противодействие пиратству, поддержание мира, гуманитарную помощь/помощь при стихийных бедствиях и операции по небоевой эвакуации.

Тесное сотрудничество Росси и КНР также препятствует возможным атакам со стороны третьих лиц. Хотя между Пекином и Москвой нет обязательств по взаимной обороне, западные военные аналитики должны, по крайней мере, учитывать возможность того, что они могут прийти друг другу на помощь в случае крупного конфликта. Хотя такой сценарий маловероятен, он, тем не менее, заставляет других задуматься, а Китай и Россия потенциальные возможности для использования рычагов воздействия.

Китай явно стремится бросить вызов США за мировое экономическое лидерство и политическое влияние, и частью этого вызова также будет растущий военный потенциал Китая в области обычных вооружений и ядерного оружия. Китайская военная модернизация и экономический потенциал создают основу для «минимального» ядерного сдерживания, достаточного, чтобы гарантировать неприемлемый ответ на любое нападение. В то же время, неограниченная китайская ядерная модернизация в поисках ядерно-стратегического превосходства над США и Россией маловероятна. Что касается возможности подключения Китая к переговорам по сокращению ядерных вооружений между США и Россией, то вовлечение Китая в процесс сокращения ядерных вооружений наталкивается на не очень прозрачный подход Китая к точному раскрытию размера и состава его стратегических и других ядерных сил.

Отношения Китая с Вашингтоном и Москвой по ограничению ядерных вооружений могут осложняться региональными военными приоритетами Китая в Азии, ввиду обязательства США по сдерживанию КНР перед региональными союзниками.

Стратегии противостояния КНР с США создают потенциальную проблему контроля эскалации, которую два государства должны решить, предпочтительно в ходе переговоров и военных обменов, а не импровизации под давлением кризиса. Наконец, необходимо, чтобы Китай участвовал в любых переговорах по контролю над вооружениями, но это возможно при выравнивании количества ядерных зарядов и боеголовок сравнимого с ядерным потенциалом США РФ. Китая крупная ядерная держава, которая справедливо настаивает на том, чтобы к ней относились как к великой мировой державе, и неуклонно наращивает свой потенциал. И России и США не заинтересованы, чтобы Китаю и дальше иметь полную свободу действий для создания непроверяемого ядерного потенциала.

Однако вовлечь Китай в переговоры по контролю над вооружениями, возможно, но следует учитывать сравнительную неопытность Китая в контроль над стратегическими ядерными вооружениями, его подозрения в отношении навязчивого международного мониторинга или проверки и его относительная непрозрачность в отношении развернутых и потенциальных ядерных сил. Между тем, Китай взял курс на улучшение военностратегического сотрудничества с Россией, включая совместное патрулирование военной авиации дальнего действия с бомбардировщиками, способными нести ядерный заряд.

Модернизация ядерных сил Китая, согласно приведенным выше аргументам, не обязательно дестабилизирует баланс сил в Азии, не говоря уже о ее последствиях за 
пределами Азиатско-Тихоокеанского региона, и направлена на достижения баланса сил в регионе и защиту своего суверенитета.

$$
* * *
$$

1. Хлопов О.А Внешняя политика США в изменяющейся структуре глобальной безопасности XXI века : монография. Москва РУСАЙНС, 2020. 260 с.

2. Reuters. Russia Told U.S. It Will Not Attend 2016 Nuclear Security Summit. Reuters, Staff, November 2014.- URL: www.reuters.com/article/2014/11/05/us-nuclear-security-usa-russia-idUSKBNOIP24K20141105. ～(дата обращения:02.08.2021).

3. Security Council. Veto List.- URL: http://www.un.org/depts/dhl/resguide/scact_veto_en.shtml. (дата обращения: 02.08.2021)

4. Russia and China Veto of Syria Sanctions Condemned as 'Indefensible' // The Guardian, 19 July 2012. - URL http://www.theguardian.com/world/2012/jul/19/russia-china-syria-sanction-veto. (дата обращения: 10.07.2021).

5. Meeting of the Security Council on the Situation Syria: Chinese and Russian Vetoes Moscow: Voltaire Network .URL: http://www.voltairenet.org/article171639.html (дата обращения: 18.07.2021).

6. US Department of State. Proliferation Security Initiative Participants, June 2014 .- URL: www.state.gov/t/isn/c27732.htm. (дата обращения: 12.07.2021)

7. Mohammed Ars. US Senate Looks to Have Ended Trump's Honeymoon with Russia// Reuters. July 29. 2017. URL: http://www.atimes.com/article/us-senate-looks-ended-trumps-honeymoon-russia/.(дата обращения: 19.07.2021)

8. Pitalev I . Russia 'Sends Very Careful Message' to Trump by Targeting Obama-Era Sanctions // Sputnik, July 29. 2017. - URL: https://sputniknews.com/russia/201707291055987722-russia-us-sanctions-obama-trump/. (дата обращения: 24.07.2021)

9. State Council. China's National Defense in 2008. Beijing: State Council Information Office of the People's Republic of China, January. 2009. - URL: http://www.china.org.cn/government/whitepaper/node_7060059.htm. (дата обращения: 05.08.2021).

10. The White House,National Security Strategy of the United States.Washington, D.C. The White House, December 2017, p. 25.

11. Dobbins J., Howard J. Shatz, Ali Wyne. Russia Is a Rogue, Not a Peer; China Is a Peer, Not a Rogue: Different Challenges, Different Responses. Santa Monica, Calif.: RAND Corporation, October 2018.- URL: https://www.rand.org/content/dam/rand/pubs/perspectives/PE300/PE310/RAND_PE310.pdf (дата обращения: 05.08.2021).

12. Schneider M. Nuclear Weapons in Chinese Military Strategy. National Institute for Public Policy. Information

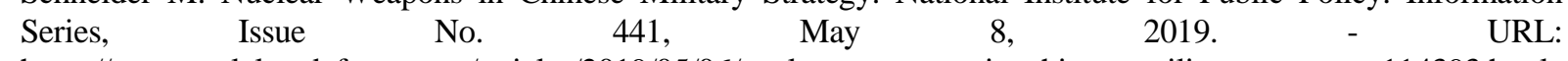
https://www.realcleardefense.com/articles/2019/05/06/nuclear_weapons_in_chinese_military_strategy_114393.html (дата обращения: 02.08.2021).

13. Robert P. Ashley, Jr. Russian and Chinese Nuclear Modernization Trends, Remarks as prepared for Delivery. Hudson Institute, May 29, 2019.- URL:https://www.dia.mil/News/Speeches-and-Testimonies/ArticleView/Article/1859890/russian-and-chinese-nuclear-modernization-trends/. (дата обращения: 01.08.2021).

14. Cunningham F.S., Fravel M.T. Assuring Assured Retaliation: China's Nuclear Posture and U.S.-China Strategic Stability // International Security. № 2, Fall 2015, pp. 7-50.

15. Kristensen, Norris R.S. Chinese Nuclear Forces, 2018 . Bulletin of the Atomic Scientists. 2018, №. 46, pp. $289-295$.

16. Hu Xijin. Cornerstone of China's Strategic Deterrence Against the US: More Nuclear Missiles and Warheads. May 27, 2021. - URL: https://www.globaltimes.cn/page/202105/1224725.shtml (дата обращения: 01.08.2021).

17. Page J. Deep Threat: China's Submarines add Nuclear-Strike Capability, Altering Strategic Balance // Wall Street Journal. Oct. 27, 2014. - URL: http://online.wsj.com/articles/chinas-submarine-fleet-adds-nuclear-strike-capabilityaltering-strategic-balance-undersea-1414164738 (дата обращения: 10.07.2021).

18. Tangredi S.J. Anti-Access Strategies in the Pacific: The United States and China // Parameters 2019 №, 49 (1-2), Spring-Summer, pp. 5-20.

19. Арбатов А., Есин В. Перспективы подключения Китая к ограничению ядерных вооружений. Центр Карнеги. Москва. 25 августа 2014.- URL: https://carnegie.ru/2014/08/25/ru-pub-56690 (дата обращения: 04.08.2021).

20. Graham Allison. What Xi Jinping Wants // The Atlantic, May 2017 .- URL: https://www.theatlantic.com/international/archive/2017/05/what-china-wants/528561/ (дата обращения: 01.09.2021). 